\title{
AS RAÍZES DA VIOLÊNCIA NA SOCIEDADE PATRIARCAL
}

por Tânia Mara Campos de Almeida*

SEGATO, Rita Laura. Las estructuras elementales de la violência: ensayos sobre género entre la antropología, el psicoanálisis y los derechos humanos. Bernal, Argentina: Universidad Nacional de Quilmes, 2003. 264 p.

O último livro de Rita Laura Segato, antropóloga e professora doutora da Universidade de Brasília (UnB), nos apresenta uma reflexão ousada e extremamente refinada dos fundamentos centrais da violência por ela identificados. Sua contribuição para os estudos na área é de diversas ordens, uma vez que contempla análises inovadoras nos interstícios e nas interseções das Ciências Sociais, da Psicanálise, do Direito e, também, da Comunicação. Esse caráter original se deve, sem dúvida, ao diálogo constante que a autora estabelece com a enorme gama de dados etnográficos sensivelmente recolhidos entre detentos, grupos religiosos, minorias sociais e internautas ao longo de sua formação acadêmica e de seus alunos, bem como de sua imersão no cenário brasileiro. Por isto, apesar de encontrar-se, até o momento, apenas publicado e comentado em seu idioma e sua terra natal, o seu livro tem muito a nos dizer.

Parte integrante da coleção "Derechos humanos: viejos problemas, nuevas miradas", dirigida por Baltasar Garzón, da Audiência Nacional da Espanha, o livro traz consigo a chancela desse renomado internacionalista, responsável pela prisão do ex-presidente

\footnotetext{
Mestre e doutora em Antropologia. Atualmente, professora e uma das coordenadoras do curso de especialização em Antropologia da Universidade Católica de Brasília (UCB).
} 
chileno Augusto Pinochet na Inglaterra e pelo pedido de extradição, em 2003, de 46 militares argentinos por crimes contra a humanidade durante a ditadura naquele país. Essa aproximação da obra com o ativismo político está presente também no fato de que projetos de intervenção junto ao cárcere, implementados em Brasília e com aplicação prevista a outras localidades, como a província de Buenos Aires, além de propostas de políticas públicas com ações afirmativas para mulheres e afro-descendentes concebidas por Segato, são elementos que compõem o arcabouço ideológico dos seus argumentos críticos e das suas proposições de transformação legal e sociocultural.

Os nove ensaios encontrados pelo leitor confluem no sentido de mostrar que as relações de gênero patriarcais são o epicentro da violência em geral e que há um esquema para a sua compreensão. A sustentação dessa afirmação está na análise dos processos de produção da violência que resultam de um mundo no qual o valor das pessoas é desigual. Tal desigualdade começa no universo familiar e é a violência moral aí onipresente, considerada normal e naturalizada, a argamassa que mantém o sistema hierárquico, reproduzindo-o num tempo de tão longa duração que se confunde com a história da própria espécie. A célula elementar das relações violentas, portanto, são as relações de gênero por serem o protótipo das relações hierárquicas - embora quem subjuga e quem é subjugado possam, em outras situações, também receber as marcas de raça, idade, classe social, etnia, nação ou região.

O primeiro capítulo, intitulado "La estructura de género y el mandato de violación", reconstrói historicamente o ato de violação da mulher, indicando que nem todas as sociedades contemporâneas e nem todas as épocas de nossa história o têm qualificado como crime, além de se apoiar sobre dados etnográficos reunidos em abordagem direta a perpetradores dos fatos de violência sexual para compreender suas motivações e seus dispositivos. Para chegar à conclusão de que a violação é uma agressão por si mesma, carecendo de fins pragmáticos próprios a exemplo de outros delitos, Segato desfoca o olhar do par clássico dos estudos na área e dos programas de prevenção da violência, "algoz-vítima", para trazer à luz a vinculação entre iguais, no espaço da fraternidade viril em que a masculinidade se reconhece, compete e dá provas mútuas de sua existência. 
Assim, identifica a origem e a reprodução da violência na intersecção entre dois eixos perpendiculares. Por um lado, o eixo vertical que traz em si a relação do dominador com o dominado, do agressor com sua vítima, e, por outro, o horizontal que denuncia o dominador com seus pares - seus semelhantes, aliados e sócios do mesmo nível hierárquico. A condição de iguais que faz possível as relações de competição e aliança entre estes últimos resulta justamente de sua demonstrada capacidade de dominação sobre aqueles desiguais que ocupam a posição inferior. Em todos os âmbitos, a geometria da violência é a mesma e caminha sobre esses dois eixos, uma vez que para ser um "igual" é necessário manter dependentes ou subordinados no eixo vertical - fato que se estende da esfera doméstica aos espaços públicos mais amplos.

Somados a isso, a força e o poder dos "iguais" são medidos em termos da sua capacidade de manter um contingente de "desiguais" sob controle e rotineiras formas de sujeição, o que obriga tal sistema a se reproduzir com intervenções bélicas cíclicas e leva à violação, enquanto um ato forçado e naturalizado de um tributo sexual a desempenhar um papel fundamental na reprodução da economia simbólica do poder, uma vez que o feminino é posto no lugar de doador de atributos que tornarão o violador um igual. Há, na verdade, um duplo vínculo entre esses eixos, explícito na tensão e alimentação mútua deles, que vão das mensagens contraditórias da ordem do status e da ordem contratual até à natureza do patriarca, que é simultaneamente autoridade moral e poder.

Aqui, a autora chama a atenção para o fato de que o patriarcado é uma estrutura hierárquica entre gêneros que não deve confundir-se com suas representações nem com a mobilidade de seus efeitos. Pois, somente por esta perspectiva inovadora é que se pode revelar, em última instância, uma "estrutura sem sujeito" que emerge feito um "mandato". Haja vista que, para os detentos entrevistados, é um enigma a forma como se sentem atacados pelos signos e gestos da feminilidade, assim como o fato de não se reconhecerem como os protagonistas de suas ações. Na fantasia que envolve a violação, é fundamental a presença imaginária ou real de outro(s) homem(ns) na 
qualidade de testemunhas de uma sorte de demonstração de virilidade. Logo, quem precisa provar que é um "igual" é alguém que se encontra em posição de subordinação em relação a outros homens. Longe de ser uma prova de poder, a violação funciona então como um intento falido para restaurar uma autoridade masculina enfraquecida que se lhes atravessa, não tanto real senão que estrutural, em razão de classe, raça, ausência de bens, dentre outros. É por isto que Segato fala de mandato de violação e de virilidade frágil, pois o homem deve violar, ainda que não seja pelas vias de fato, ao menos de maneira alegórica ou metafórica. Enfim, o violador não atua porque tem poder, mas justamente porque deve estar constantemente obtendo-o, uma vez que o status expropriado nunca foi inteiramente ganho.

No segundo capítulo, "El género en la antropología y más allá de ella", a pesquisadora empenha-se em estabelecer a diferença entre o jogo das identidades de gênero e o cristal de status que as constela. Afinal, é urgente atravessar as representações, as ideologias, os discursos cunhados pelas culturas e as práticas de gênero para aceder à economia simbólica que instala o regime hierárquico e o reproduz. O patriarcado é, portanto, uma estrutura de relações entre posições hierarquicamente ordenadas que tem conseqüências no nível observável, mas que não se confunde com ele. Logo, a análise defendida por Segato deve exibir a diferença e mostrar a mobilidade dos significantes na relação com o plano estável da estrutura que os organiza e lhes dá sentido e valor relativo.

Assim, o patriarcado é entendido como pertencendo ao extrato simbólico e, em linguagem psicanalítica, como a estrutura inconsciente que conduz os afetos e distribui valores entre os personagens do cenário social. A posição do patriarca é, portanto, uma posição no campo simbólico, que se transpõe em significantes variáveis nas distintas interações sociais. Por esta razão, o patriarcado é, ao mesmo tempo, norma e projeto de auto-reprodução, o que o leva a censurar e controlar a fluidez, as circulações, as ambivalências e as formas de vivência de gênero que resistem a ser enquadradas na sua matriz heterossexual hegemônica. O ensaio, por sua vez, mostra que, comparada com outros exemplos etnográficos, a construção ocidental de gênero é uma das 
menos criativas e sofisticadas, pois fixa a sexualidade, a personalidade e os papéis sociais no dimorfismo anatômico.

No capítulo seguinte, "La célula violenta que Lacan no vio: un diálogo (tenso) entre la antropologia y el psicoanálisis", a autora trata das possibilidades e impossibilidades do trabalho conjunto entre a Antropologia e a Psicanálise, oferece pautas para a colaboração entre as disciplinas e monta um diálogo entre os achados etnográficos de Maurice Godelier e um dos centros teóricos da perspectiva lacaniana: "a mulher é o falo enquanto que o homem tem o falo". Esta máxima faz referência a um ato de apropriação que, ainda que instalado na cultura da espécie ao largo de uma história identificada com o tempo filogenético, está longe de ser pacífico. E mais, este ato de apropriação é compelido a reproduzir-se por meios violentos, regular e cotidianamente.

O referido tema do capítulo três segue desenvolvido no capítulo seis - "La economia del deseo en el espacio virtual: hablando sobre religión por Internet" -, como indica a própria Segato. Aqui, a partir do registro e da análise de casos de interação virtual sobre temas de credo religioso, o caráter onipotente do sujeito contemporâneo usuário de Internet e sua "telescopia" são revelados. De modo curioso, vemos que uma relação que aparentemente reformula as relações de gênero e parece transcender o determinismo biológico, ao dar a impressão de que o corpo pode ser inventado discursivamente no ambiente cibernético, gera um sentimento de onipotência e multiplica a agressividade dos envolvidos. Trata-se de seguir desenvolvendo a antropologia do sujeito proposta no terceiro ensaio, pois mostra a especificidade do sujeito contemporâneo ocidental que busca relacionar-se de modo a não sentir os limites impostos pela materialidade dos corpos. Devido à inspiração psicanalítica, o corpo é entendido aqui como o primeiro outro, a primeira experiência do limite, a primeira cena da incompletude e da falta que, ao ser denegado, todas as outras formas de alteridade deixam de constituir o limite que possibilita ao sujeito qualificar-se enquanto um sujeito social. Estamos, por conseguinte, frente a uma realidade regressiva, consequiência da fantasia narcisista de completude e da recusa em reconhecer-se castrado, índice mesmo da finitude humana. 
Já o capítulo "La argamasa jerárquica: violencia moral, reproducción del mundo y la eficácia simbólica del derecho" coloca a violência moral no centro da reprodução do regime de status, tanto no caso da ordem de gênero como no da ordem racial. A violência moral não é vista como um mecanismo espúrio nem, muito menos, dispensável ou erradicável da ordem de gênero - ou de qualquer ordem de status - senão inerente e essencial. Portanto, não se prioriza aqui - igualmente em outras análises - seu caráter de primeiro momento na escalada da violência doméstica, ou seja, de passo prévio à violência física. É no seu papel como usina que recicla diariamente a ordem de status e que, em condições normais, se basta para fazê-lo, que cai a ênfase.

Em toda a obra se afirma que a moral e o costume são indissociáveis da dimensão violenta do regime hierárquico. Pois, a esfera da lei é concebida como regida pela ordem do contrato, enquanto a esfera do costume é entendida como regida pela ordem do status - imune em grande medida à pressão do contrato jurídico moderno sobre ela. Tanto esse como o quinto capítulo, "Las estructuras elementales de la violência: contrato y status en la etiologia de la violência”, defendem a necessidade de legislar na ótica dos direitos humanos. Esta posição se explica pela capacidade de o Direito simbolizar os elementos de um projeto de mundo, criar um sistema de nomes que permita constituir a lei num campo em disputa. A eficiência do Direito é assim entendida de acordo com a eficiência de um sistema de nominação que cria realidade e permite comprovar a natureza histórica do mundo. É também neste capítulo, homônimo do título da obra, onde aparece uma primeira síntese da tese central, que reside no procedimento chamado de "exacción del tributo de gênero", a condição indispensável para o credenciamento dos que aspiram ao status masculino e esperam competir ou aliar-se entre si, regidos por um sistema contratual.

Após esse ensaio, surgiu então o local adequado para o sétimo capítulo, "La invención de la naturaleza: família, sexo y género en la tradición religiosa afrobrasileña". Tal texto etnográfico, resultado de longo trabalho de campo junto ao Xangô do Recife, representa o 
ingresso da pesquisadora na reflexão sobre gênero, trazendo à tona uma sociedade andrógina, em que não é adequado falar de heterossexualidade ou homossexualidade, já que se trata de uma visão do mundo que segue a padrões de gênero distintos dos ocidentais. Esta outra maneira de "inventar a natureza", radicalmente antiessencialista e antideterminista, vincula-se à experiência da escravidão, que rompeu o cânon patriarcal africano e criou outro estatuto da família, descendência, sexualidade, personalidade e divisão sexual do trabalho. A partir dessa tradição crítica e marginal, um conjunto de enunciados que operam, por meio de um discurso irônico e crítico, conseguiu elaborar a desconstrução do horizonte patriarcal na sociedade circundante.

É no oitavo capítulo, sob o título "Género, política e hibridismo en la transnacionalización de la cultura Yoruba", que a etnografia anterior alcança seu sentido pleno. Apesar das desvantagens e das privações impostas pela escravidão, a capacidade de a civilização yoruba difundir-se e impor seus sistemas de crença e convivência em sociedades distantes (Cuba e Brasil durante a colônia e, numa onda expansiva recente, os Estados Unidos e os países da órbita do Rio da Prata) está estreitamente vinculada com a maleabilidade, a androginia e a ausência de determinismo biológico de sua concepção de gênero. Também, neste ensaio, é apresentada a maneira como três estudiosos diferentes (uma yoruba radicada nos EUA, um estadunidense e a própria autora, latinoamericana) formulam e equacionam as particularidades dos padrões de gênero yoruba, o que depende diretamente de seus interesses e da inserção geopolítica de sua tarefa intelectual.

Essas três interpretações particulares da construção de gênero são analisadas por Segato enquanto discursos posicionados que expõem a economia política do discurso etnográfico. Todavia, todas as interpretações apontam incontestavelmente para o caráter antiessencialista das concepções de gênero nessa cultura. No caso particular da versão afrobrasileira, o uso híbrido dos termos próprios da família patriarcal, como a posição do pai, da mãe, do filho primogênito e a desconstrução das idéias de conjugalidade, 
primogenitura, autoridade e herança, acaba por desestabilizar a estrutura e minar as bases da matriz heterossexual do patriarcado. É assim que os membros do culto satirizam as relações de status, o Estado brasileiro com sua permanente exclusão dos afrodescendentes e desacatam os imperativos do patriarcado simbólico, desestabilizando e corroendo de modo irreverente a ordem vigente dentro do universo religioso.

Finalmente, o último capítulo, "Los princípios de la violência", que parafraseia o nome do livro, trata-se de uma conferência proferida no ano passado na Espanha, no marco de um curso sobre violência de gênero organizado pelo juiz Baltasar Garzón. Dedicada a expor de forma sintética as teses centrais que atravessam a obra, esta breve seção se refere ao papel da violência na reprodução da ordem de gênero e à interdependência entre violência e gênero para afirmar que a articulação violenta é paradigmática da economia simbólica de todos os regimes de status. É este olhar da autora para o eixo horizontal dos iguais que nos mostra não haver prazer em jogo nas violações, senão enfrentamento dos homens por intermédio de suas "mulheres", bem como que sugeriu a utilização, para o título da obra, da noção lévi-straussiana de "estruturas elementares".

O capítulo também reafirma, exemplificando com o discurso híbrido, desestabilizador e irônico do códice religioso afrobrasileño, entendido como uma forma efetiva de reflexividade, uma possível saída da humanidade da armadilha estática do estruturalismo e do bastidor simbólico, que domina as relações de gênero, em direção a uma época pós-patriarcal. A solução ora postulada é que estas posições relativas, ao liberarem-se paulatinamente (através das lutas históricas do movimento social e das trocas nas práticas sociais e sexuais) de sua fixação ideológica no dimorfismo anatômico, serão cada vez mais percebidas como lugares de passagem, abertas ao trânsito dos sujeitos. Mas para que isto resulte numa transformação efetiva do mundo, será fundamental a proliferação de formas simbolizadas para a realidade desses trânsitos e desta circulação, o que possivelmente também trará soluções para a violência inerente à reprodução de todos os regimes marcados pelo status. 
Afinal, a humanidade sairá de sua pré-história somente quando deixar para trás a estrutura simbólica patriarcal. Por isso, Segato ressalta que o primeiro passo para transformar a relação de subjugação é a consciência reflexiva. Tal avanço, que se constitui na compreensão oferecida pela Antropologia e pela Psicanálise da esfera da intimidade, é a única forma de desestabilizar a arquitetura do sistema. É este o subsídio que esses saberes podem oferecer ao Direito para auxiliá-lo na tarefa de desarmar a sociedade. Só com a reforma da intimidade é que será possível desmontar a escalada da violência societária, do nível microscópico das agressões domésticas ao macroscópico das guerras. Ou seja, o combate às formas rotineiras de violência é possível, desde que se entenda esta luta como parte de um trabalho de desestabilização e de erosão da própria ordem de status, não como mero paliativo - simples correção dos excessos de violência.

Além disso, a autora diz também ser imprescindível a cooperação entre o Direito e a Comunicação, já que o primeiro tem a capacidade de transformar as relações sociais e o segundo de democratizar essas mudanças. Os direitos humanos estabelecem metas e objetivos para a sociedade, criam uma nova moralidade e, ao dar nome às queixas e aos desejos coletivos, podem cumprir seu papel pedagógico e transformador.

Paralelamente, a saída da violência de gênero apresentada por Segato não é o registro de reincidentes nem a psicologização do violador, senão a inscrição na lei de todas as formas de violência de gênero como experiências não desejáveis para uma sociedade, a organização e a escuta da experiência das vítimas, a elaboração de políticas públicas que favoreçam aos violadores desidentificar-se dos ditados impostos acerca da mulher genérica, além da disseminação de discursos que ponham em xeque o dado como lei natural. Afinal, este personagem violador, peça determinada em um regime violento, dele só poderá livrar-se por intermédio da convivência em um mundo de outros modificados: uma mulher cuja liberdade não o ameace, companheiros que não lhe imponham condições para pertencer e antagonistas que não mostrem suas mulheres enquanto extensão de suas posses e de sua honra. 